\title{
"Dios los crea y el viento los amontona": Trânsitos afetivos de estudantes intercambistas na capital mineira
}

\author{
ANTONIO AUGUSTO OLIVEIRA GONÇALVES \\ Universidade Federal de Goiás, Goiânia, Goiás, Brasil
}

DOI 10.11606/issn.2316-9133.v28i1p14-32

\begin{abstract}
resumo Neste artigo, busco relatar algumas experiências afetivossexuais de estudantes intercambistas em Belo Horizonte (MG). Estes/as universitários/as vêm de cidades da Argentina para estudar na capital mineira por um período de seis meses e residem nas moradias universitárias da UFMG (Universidade Federal de Minas Gerais). Pelas observações etnográficas e entrevistas, notei que a vida no intercâmbio era filtrada pela existência social das moradias, pelas relações que ali se principiavam. Neste contexto de coabitação, havia certas práticas disciplinares, uma arquitetura panóptica e um controle da entrada de visitantes, isto forçava os/as intercambistas a se envolver em trocas de objetos e favores para tornar possíveis seus encontros afetivos. A circulação de bens além de forjar uma trama de reciprocidade entre os/as residentes, também afetava os seus itinerários urbanos, conformando-os numa escassa mobilidade, circunscrita na região da Pampulha.
\end{abstract}

palavras-chave Intercâmbio acadêmico; Panóptico; Socialidades; Sentidos do lugar; Trajetos urbanos.

Dios los crea y el viento los amontona: affective transits of exchange students in the Capital of Minas Gerais

abstract This paper is aimed at relating some affective and sexual experiences of exchange students in Belo Horizonte (MG). These university students come from cities in Argentina to study in the Capital of Minas Gerais for a six months period and reside in the university residences of the Federal University of Minas Gerais (UFMG). From the ethnographic observations and interviews, I noticed that life in the interchange was filtered by the social existence of the dwellings, by the relations that began there. In this context of cohabitation, there were certain disciplinary practices, a panoptic architecture and a control of the entrance of visitors that forced the exchange students to engage in exchanges of objects and favours to make possible their affective encounters. The circulation of goods, in addition to forging a pattern of reciprocity among residents, also affected their urban itineraries, making them less mobile, circumscribed in the Pampulha region.

keywords Academic exchange; Panopticon; Socialities; Senses of the place; Urban 
paths.

\section{Prolegômenos}

Neste texto, busco relatar as trajetórias afetivossexuais de estudantes intercambistas em Belo Horizonte (MG), alunos/as estrangeiros/as da Universidade Federal de Minas Gerais (UFMG), provenientes da Argentina que residiram, em média, durante seis meses na capital mineira. Devidos aos acordos bilaterais com as universidades, alguns/as desses/as estudantes viviam nas moradias universitárias da UFMG situadas no Bairro Ouro Preto. Nas primeiras incursões de campo, o local de residência dos/as intercambistas parecia tão somente um de tantos expedientes etnográficos possíveis para compreender as vivências sexuais deles/as, o que incluía, além de outros aspectos, elementos como o gênero, etnia/nacionalidade, tempo de participação em processos migratórios, idade e histórias de vida. Entretanto, na medida em que avancei nas observações e nas entrevistas, apercebi que as moradias da UFMG detinham uma centralidade nos relacionamentos sociais dos/as intercambistas; era principalmente a partir desse microcosmo que a maioria deles/as tecia contatos, fazia amizades e se relacionava sexualmente, de tal modo que alguns/as se viam inscritos/as numa "economia política do sexo". Gayle Rubin (1986) propõe esta expressão para designar como as atividades sociais e políticas não estão desvinculadas do exercício da sexualidade:

Las preocupaciones tradicionales de la antropología y la ciencia social como la evolución de la estratificación social y el origen del estado - tienen que ser reelaborados para incluir las implicaciones del matrimonio de primos cruzados matrilaterales, el excedente extraído en forma de hijas, la conversión de las vidas de las mujeres en alianzas matrimoniales, [...] reconociendo[se] la recíproca interdependencia de la sexualidad, la economía y la política, sin subestimar la plena significación de cada una en la sociedad humana. (RUBIN, 1986, p.140-141).

Nesta "economia política do sexo", os/as intercambistas se envolviam em trocas de objetos e favores com os/as moradores/as brasileiros/as, uns/as e outros/as trocavam entre si, colchões, chaves, trafegavam informes de quartos recém-desocupados para facultar o pernoite de algum/a visitante. A estreiteza das relações entre eles/as não se explicava apenas em termos de afinidades e formação de grupos, mas também repercutia arranjos mais estruturais, como, por exemplo, as políticas da instituição responsável pela administração das moradias da UFMG - Fundação Universitária Mendes Pimentel (FUMP) -, a disposição arquitetônica dos blocos e o sistema de vigilância nas portarias. Os/As intercambistas, na qualidade de recém-admitidos/as, tinham um tratamento mais restritivo nas portarias, uma vez que não podiam receber visitas após as 22 horas e nem estavam autorizados/as a hospedar um/a visitante durante uma noite. Enquanto que entre os/as internos/as de longa admissão - i. e., os/as residentes nacionais - imperava até então uma "diplomacia do 
fingimento" (GASPAR-NETO, 2014), ou seja, os/as moradores/as brasileiros/as navegavam nos labirintos dos preceitos regulamentares e até mesmo zombeteavam deles em certos momentos e os porteiros podiam criar dificuldades para admitir a entrada de um/a visitante, mas ao final ele/a passaria noites a fio, com pouca ou quase nenhuma intervenção dos funcionários. Este quadro atualmente passa por transformações políticas. Desde 2011, a FUMP tenta implementar uma norma que proíba os pernoites dos/as visitantes ou ao menos regulamente um parâmetro máximo para estadia deles/as nas moradias.

Se as experiências afetivossexuais dos/as intercambistas dependiam, por um lado, dessa entrelaçada organização social que eles/as forjaram em conjunto com os/as demais residentes, por outro, ambos/as tinham que realizar suas trocas de objetos e favores levando em consideração a arquitetura do lugar. As duas unidades do complexo de Moradias Ouro Preto da UFMG (MOP I e II) se arranjam espacialmente de forma semelhante a um claustro, os blocos estão ladeados e compõem três traços retilíneos imaginários que combinados entre si formam um retângulo, donde o ponto médio deles ora se localiza o prédio da Administração na unidade I (MOP I), ora uma praça na unidade II (MOP II). A maioria dos blocos está exposta a visibilidade uns dos outros. Não há medianeiras neles. Onde não há vidros transparentes, há basculantes à altura do parapeito, onde não há portas, há sacadas. $\mathrm{O}$ que não é visto nesse grande pátio interno, pode ser observado através das rondas externas dos porteiros, contornando os blocos a partir das passagens para o estacionamento ou, quem sabe, percorrendo o retângulo de uma ponta a outra. Nesse momento, são as sacadas que se tornam conspícuas, enquanto as janelas e as portas, no lado intestino do claustro, auxiliam os passos airosos do vigilante no estacionamento.

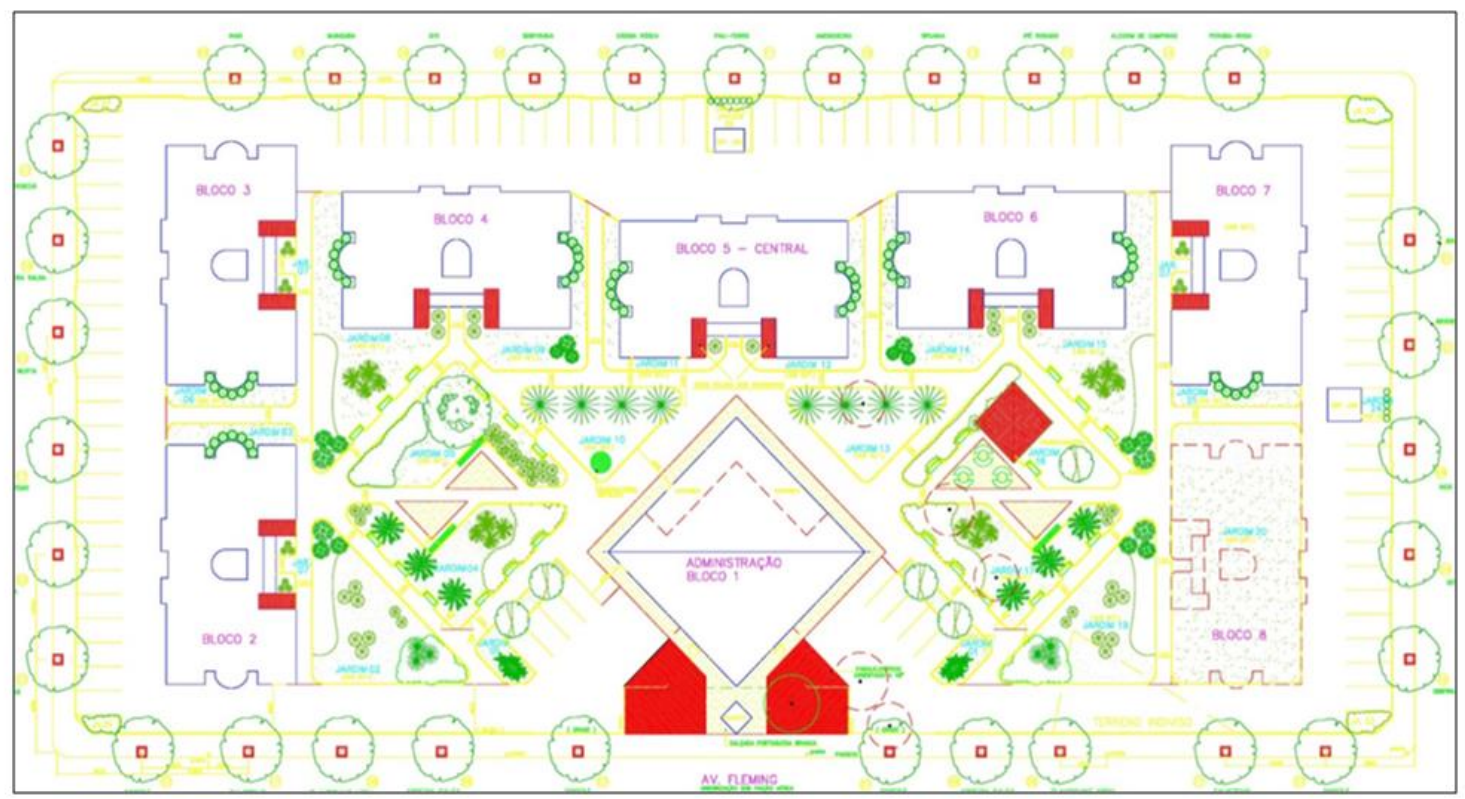

Figura 1. Planta aérea MOP I. Fonte: DMAE/UFMG, 2016 


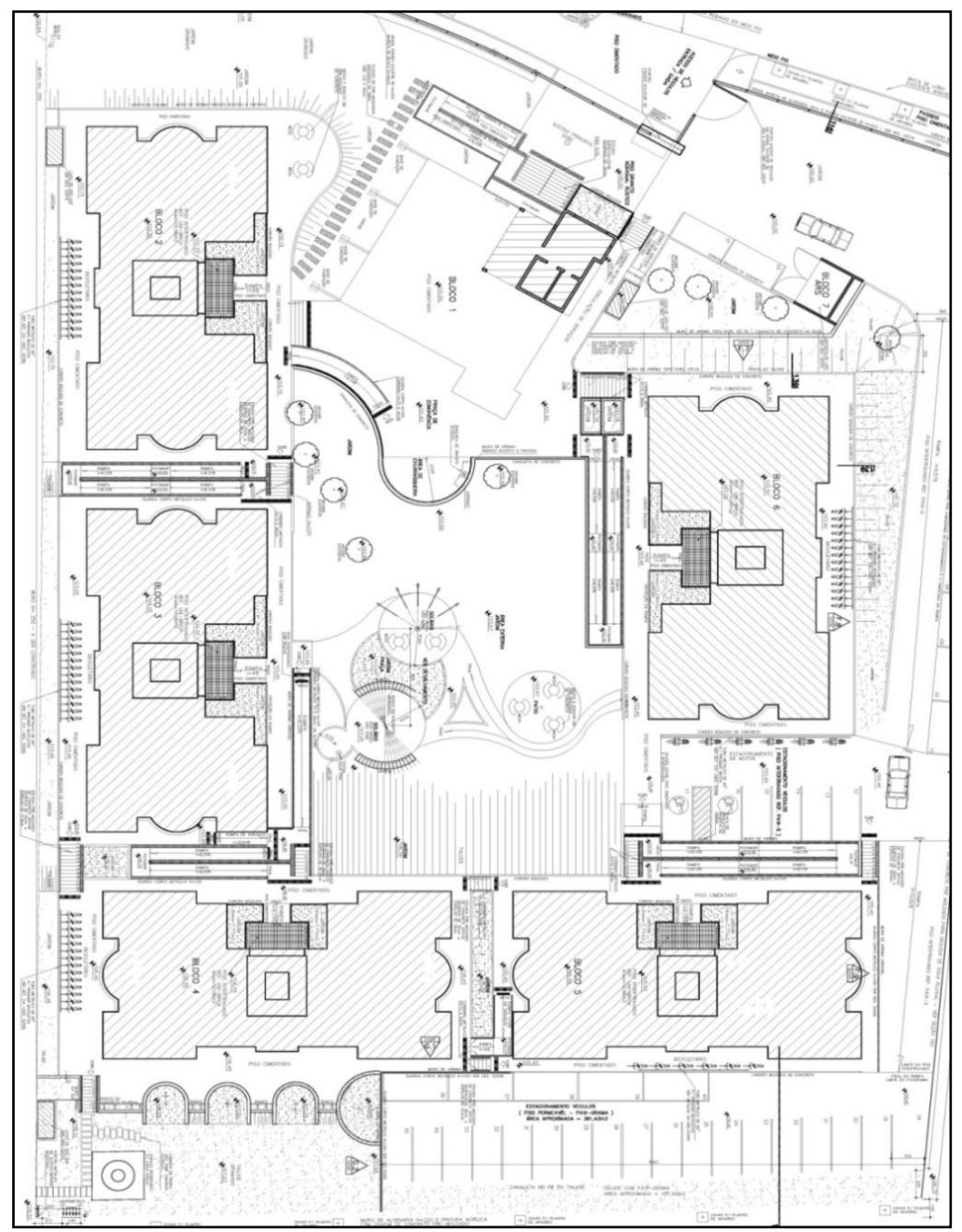

Figura 2. Planta aérea MOP II. Fonte: DMAE/UFMG, 2016.

Pelas descrições e as imagens acima, se pode averiguar a existência de um dispositivo panóptico e disciplinar (FOUCAULT, 2010) nas moradias da UFMG que era burlado mediante algumas práticas. Por exemplo, para que os encontros íntimos dos/as intercambistas fossem exequíveis, eles/as necessitavam do auxílio dos/as moradores para fornecer os seus nomes nas portarias, assim os/as visitantes dos/as intercambistas poderiam pernoitar nos quartos. Além disso, um/a morador/a eventualmente emprestava seu dormitório a um/a intercambista quando estivesse numa viagem, aquiescendo o trânsito de chaves e/ou colchões entre os blocos. Esta troca de objetos, solfejada pela permuta de nomes de moradores/as e intercambistas nas MOP I e II, implicava, tal como propõe Marcel Mauss (2003) em Ensaio sobre a dádiva, a mistura dos espíritos nas coisas e das coisas nos espíritos. As almas reificam-se e o espectro reificado sobrepuja a sua realização empírica para representar vínculos espirituais entre pessoas e grupos.

As trocas de dádivas entre os/as residentes permitiam que as experiências afetivas dos/as estudantes estrangeiros/as fossem vivenciadas num espaço esquadrinhado pela disciplina, ao mesmo tempo em que produzia uma "cascata de pequenos vínculos sociais" (LÉVI-STRAUSS, 1976, p. 99), expressa na circulação de chaves, nomes, colchões e 
empréstimos de quartos. Isto corresponde, de alguma maneira, ao domínio dos dons recíprocos, no qual um/a se sente à vontade para pedir, ficando um/a segundo/a obrigado/a a emprestar e em ambas as direções, sempre para além do que fora pedido e emprestado (LÉVI-STRAUSS, 1976). Dito de outro modo, por meio da socialidade nas moradias, os/as intercambistas construíram uma trama de vínculos e interdependências (STRATHERN, 1999; ELIAS, 2001) de tal modo que o ato sexual entre duas pessoas no quarto da MOP quase sempre envolvia relações sociais mais amplas com os/as demais moradores/as, num intrincado sistema de trocas, trânsito espiritual e reciprocidade em que a díade se enleava.

A pesquisa se desenrolou de 2015 a 2016. Nesse intervalo de tempo, eu realizei observações etnográficas com intuito de registrar o repertório simbólico de práticas e significados afetivos nas MOP I e II, captar os referenciais êmicos empregues entre os meus sujeitos de pesquisa (DIAS, 2006). Além disso, ao longo de quase um ano de trabalho de campo, entrevistei mais de 10 estudantes intercambistas, advindos de distintas regiões da Argentina, com idades de 21 a 25 anos.

Além desta introdução, o artigo se abre a dois nichos etnográficos. Na seção seguinte, busco descrever as relacionalidades e diferenciações do espaço/lugar dentro das moradias a partir do par êmico praça/apartamentos. Na terceira seção, posiciono o flanco existencial das moradias no campo mais amplo de trajetos urbanos dos/as intercambistas na região da Pampulha e em Belo Horizonte, denotando como a socialidade porta adentro, no interior das moradias, reflui nos percursos citadinos desses sujeitos.

\section{Salas e praças: sonoridades, interstícios e o lugar/espaço}

Ao ir a festas na moradia, frequentemente me deparava com pessoas dispersas ali, conversas acolá, cervejas postas e retiradas da geladeira situada ao fundo das cozinhas americanas. Eventualmente alguém se dirigia ao notebook para mudar o ritmo das músicas, cingir a cadência dos movimentos para o funk, o sertanejo, as músicas de Enrique Iglesias. A "dimensão acústica" (FELD, 1996) no simples dedilhar digital afetava o deambular na pista de dança, sujeitos saiam do parapeito da cozinha e se encorajavam a flertar com alguém noutro extremo, às vezes, sob a desculpa de oferecer bebidas ou ir ao banheiro. A experiência da dança trazia de volta as modulações dos sons que "[eram] percebidos como pontos de conexão acima e abaixo, dentro e fora, eco e reverberação, ponto-fonte e difuso" (FELD, 1996, p. 97-98, tradução nossa).

A sala, mais do que qualquer outro cômodo dos apartamentos e quitinetes, ocupava o centro da vida social nas moradias. Perquirir os encontros afetivossexuais nos quartos me obrigava a passar pela existência social representada por aquele cômodo, não só devido aos subterfúgios arquitetônicos, mas também pela indexação sonora dos encontros, numa espécie de "acostemologia" (FELD, 1996; 2015) ${ }^{1}$ dos flertes: frequentemente eram mais os

\footnotetext{
${ }^{1}$ A "acostemologia" de Feld (1996) condensa, de um lado, a percepção e as sensibilidades sonoras e, de outro, por quais inscrições auditivas se chega a saber o que se sabe, ou seja, trata-se de uma epistemologia nativa das sonoridades. No campo, eu diria que as músicas de Shakira, Anitta, Mc Sapão, por exemplo, influíam, de sobremaneira, nos desfechos afetivos, numa dinâmica não tanto causal, senão de entrecruzamento assimétrico da encarnação sonora
} 
circunlóquios, danças e olhares nos salões que conduziam aqueles/as jovens aos aposentos, através das trocas de dádivas, do que o contrário.

A intercambista Marie-Claude descia as escadarias do bloco onde morava, atravessava os jardins para se dirigir a um desses apartamentos e, quando colocava os pés pelo umbral das salas, dizia sentir-se uma "estrela":

Marie-Claude: também comecei tipo a ir pra festas, de a conhecer a brasileiros e aí sim já começar a procurar pessoas, de estar com muitas pessoas, de me sentir uma estrela, cheguei um momento que eu ia pra festa, por exemplo, chegava às uma, porque eu não gosto de ir pra festa cedo, e chegava e todo mundo "ohh Marie-Claude". Todo mundo me conhecia, então era como que $i b a$ cumprimentando todo mundo [...] eu acho que cumprimentava todo mundo porque era aqui na moradia. Nunca sai da moradia.

À medida que Marie-Claude embrenhava entre os corpos propínquos para ir ao encontro de amigos/as na moradia, lançar seus ombros ao abraçá-los/as, emitir acenos, dar beijos nos rostos de seus/suas conhecidos/as, ela efetivamente deambulava entre os círculos de pessoas que se punham na soleira da cozinha ou na abertura das janelas para incinerarem seus cigarros e observarem o que se passava na praça. Ao cumprimentar "todo mundo", ela sabia que "todo mundo" a reconhecia.

Os cumprimentos de Marie-Claude nas festas eram um bom sinal da trama de relações estabelecidas por ela nas moradias. Ao "procurar pessoas" ela não estava sozinha. Os vínculos com os/as amigos/as e as suas relações sexuais, ao final de uma festança, confundiam-se de tal modo que, ao "conhecer a brasileiros", se manifestavam como plano de fundo àquelas relações sinalizadas pelos seus cumprimentos. Talvez, tenha sido por conta disso que MarieClaude "nunca" tenha saído dali para ir a festas fora da moradia. Mesmo quando decidia "transar com um cara", a interdependência com aqueles elos sociais se fazia sentir:

Marie-Claude: eu moro com três meninas mais, é que no quarto tem todas as camas, aí dentro do quarto e não tem porta. Do quarto até a sala não tem porta. Então se eu estou transando com um cara tranquilamente a pessoa que entre dentro do meu apartamento vai ver e eu já me sinto incomodada. E eu sempre pido o quarto pra minha amiga, levo o cara aí ou o cara mora aqui eu vou pro quarto do cara ou se uma menina quer transar lá eu vou pra quitinete dos meninos que moram aqui no bloco $3 \mathrm{e}$ não sei tipo eu não tenho minha privacidade se eu quero transar com um cara eu tenho que, eu dependo muito das outras pessoas.

dos movimentos com a figuração acústica do lugar, ou seja, no liame entre os meneios corpóreos e o constante trânsito dos sujeitos na sala das quitinetes. 
Essas dependências mútuas retomam o teor argumentativo sobre a circulação de dádivas, mas, aqui, visualiza-se o intercurso de pessoas e favores. Pode-se até averiguar pelo testemunho de Marie-Claude certas predileções, o receio de ser vista transando no dormitório e/ou na sala da quitinete, os pedidos à amiga, o pernoite dela em outro bloco, permitindo, assim, a "privacidade" da colega de quarto.

$\mathrm{O}$ que se iniciava nas festas podia ter reverberações bem diversas, contudo a imbricação de expectativas, favores e trocas com as experiências afetivossexuais era a tônica. As festas materializavam, inclusive, o conceito de "socialidade" (STRATHERN, 2006) ${ }^{2}$ através das danças de modo que os acenos de Marie-Claude transcendiam o mero mimetismo cerimonioso, desvelando nexos entre o dispositivo panóptico da MOP e as trocas de favores que, por sua vez, levavam ao estabelecimento de "multilocalidades" (RODNAN, 2003). Por outras palavras, a textura relacional "mopiana" ${ }^{3}$ vai além dos muros da moradia e lança suas linhas de continuidade nos percursos urbanos dos/as intercambistas, tal como demonstrarei mais adiante. Porém, antes de caminhar pela orla da Pampulha, inspirando-me no flâneur de Baudelaire (BENJAMIN, 1994), quero rever as maneiras como as espacialidades se convertiam em lugares na MOP (CASEY, 1996; TUAN, 1983; AUGÉ, 1994).

A socialidade mopiana tendia a relacionar diferentes sujeitos, de um lado, e os distintos lugares das interdependências entre eles, de outro. Por exemplo, nem sempre as festas se iniciavam como celebrações abertas aos/as habitantes dos blocos vizinhos, da outra moradia - MOP I ou II - e aos/as visitantes. Por vezes, uma reunião, um jantar entre os/as intercambistas redundava em uma grande festa, colocava-se música alta e as pessoas já não permaneciam sentadas com as refeições dispostas ante a elas. O que transformava os jantares em festas era aquilo que inversamente os definia: o grau de maior ou menor fechamento do grupo em relação aos demais. Organizar uma reunião nas quitinetes e não postar algo sobre o evento no grupo da moradia no Facebook já sinalizava que os/as reunidos/as preferiam a convivência dos/as próximos/as, de modo mais reservado. Porém, aqueles/as que ali estavam podiam receber visitas, mais e mais pessoas adentravam pela porta e logo a ocasião se convertia em uma pândega.

Persistia, então, uma separação um tanto tênue entre os apartamentos e as praças; às vezes, os primeiros se tornavam pequenas camarilhas de um teatro social que ocorria no

\footnotetext{
${ }^{2}$ Por socialidade entende-se o significado que Marilyn Strathern confere a esta expressão a partir das formulações melanésias, designando "a criação e manutenção de relações sociais" (STRATHERN, 2006, p. 40). Strathern (1999) prefere o termo socialidade à expressão "sociabilidade”, conceito derivado das proposições teóricas de Simmel. Em inglês, "sociability" aponta para uma experiência empática em comunidade, o que exprime certa sentimentalização das relações sociais na leitura da autora. Isto conduz a reducionismos de todo tipo, da reciprocidade ao altruísmo, da socialidade à sociabilidade, como se as relações remetessem apenas a algum lado afável da vida social ou estivessem sempre imbuídas de alguma conotação positiva (STRATHERN, 1999).

${ }^{3}$ Categoria êmica que designa os/as residentes no Complexo de Moradias Ouro Preto - MOP I e II. Mopiano/a é uma flexão substantivada a partir da sigla MOP.
} 
claustro entre os prédios, principalmente, em uma das quatro festas oficiais das moradias ${ }^{4}$, pois das janelas tinha-se uma visão privilegiada do centro de convivência e das praças, a ponto de se visualizar parte da trama de pessoas escadarias abaixo, sobretudo, no terceiro e quarto andares dos blocos. Assim, qualquer um/a podia ver seu/sua "crush" 5 ou um/a pretendente antes de descer para a festança, precavendo-se de certos incidentes fortuitos ao flertar com alguém.

Em outras circunstâncias, eram as escadarias de um dos blocos que davam acesso aos apartamentos, que se transfiguravam no chamariz das atenções coletivas, e, com isto, as salas se tornavam um "habitat de significados" (HALL, 2005). A dialética abertura/fechamento de um grupo de intercambistas e seus/as vizinhos/as, brasileiros/as ou não, em relação aos/as demais se exprimia no binômio praça/apartamentos. Klara, por exemplo, nos dá um indicativo disso a partir da descrição da rotina de encontros com suas amigas intercambistas:

Entrevistador: si tú y tus amigas quieren juntarse ¿dónde quedan?

Klara: por lo general acá o en de las chicas que es en bloco al lado.

Entrevistador: pero abajo, ¿no?

Klara: pocas veces, por general si nos juntamos abajo es con los otros chicos también, pero si muchas veces nos juntamos a comer o hablar, o tomar café allá en la casa de las chicas más que nada.

Pelo relato de Klara permanecer com "las chicas" significava quase sempre estar em uma das quitinetes habitadas por elas. Caso quisessem se integrar com os/as demais, desciam para as praças, encontravam com "los otros chicos" intercambistas. Lucie, por sua vez, quando aportou em Belo Horizonte, ainda não tinha companheiras de quarto. Ela nos conta a dificuldade de driblar esse relativo grau de fechamento e diferenciação dos/as intercambistas via quitinetes:

Lucie: pero lo que me paso fue, como, que ya vivir con alguien te da como, o sea, una amistad es como una relación diferente. Todo los [que] estaban acá eran como amigos o tenían una relación con la gente que vivían. Como yo no vivía con nadie, tenía buena relación, conocía gente, pero [...] como la gente que vivía con alguien y estaba acompañada de esa persona, como que travaban la relación con ellos. Yo tenía relación con las de las otras moradias, con las otras quitinetes pero como no vivía

\footnotetext{
${ }^{4}$ De acordo com uma interlocutora de pesquisa, as quatro festas são: "a primeira é a recepção dos calouros; depois vem a festa junina, que foi recentemente, sábado passado; a recepção dos calouros do segundo semestre; e a festa à fantasia”.

${ }^{5}$ Trata-se de um emprego nativo da palavra, derivado do aplicativo telefônico Happn. Portando o telefone, uma pessoa, ao caminhar pela cidade, cruza com outras em seu percurso. Assim, um dispositivo de localização geográfica no aplicativo lista uma série de perfis de pessoas com quem o/a usuário cruzou ao longo do dia. Caso ambos/as vejam os perfis um/a do outro/a e se interessem mutuamente, eles/as darão um “crush", uma combinação que logo ativará uma janela de trocas de mensagens virtuais pelos celulares.
} 
con ellos, no había hecho como una amistad, entonces como que por ahí estaba mucho tiempo sola, por eso, porque no tenía a nadie con quien vivir por lo general vos te cerras amigo de la persona con que viviste. Las chicas de la otra quitinete se hicieron amigas las cuatro, pero porque viven juntas, entonces empiezan a convivir, por ahí las veía como a cada dos días y me costó, como, entablar, así, una relación al principio por vivir sola.

Lucie é uma personagem interessante para a presente etnografia porque, pelo fato de não dividir o quarto com outra pessoa de início, declara as dificuldades de "entablar" amizades com os/as habitantes das outras quitinetes e, assim, começou a trafegar por entre as duas moradias, fez viagens com algumas conhecidas da MOP I, mas também mantinha relações com pessoas da MOP II. Dessa maneira, implicitamente, ela tenta navegar por entre os interstícios das relacionalidades construídas no decurso de meses e, de alguma maneira, Lucie expressa como tais laços guardam correspondência com seus lugares de tessitura: "por lo general vos te cerras amigo de la persona con que viviste". Veja que, em seu relato, a natureza do vínculo e o seu contexto aparecem enquanto categorias recíprocas, uma evade a circunscrição da outra, ou seja, as corporalidades separadas por alguns palmos entre si e a quitinete que as coaduna tornam-se domínios interdependentes mediante as experiências diárias que atam seus/as habitantes uns/as aos/às outros/as (CASEY, 1996).

Se o mesmo desenlace semântico parece lançar luzes tanto sobre a diferenciação de socialidades pelas quitinetes, quanto na evocação solitária de Lucie, então se entrevê dobras contraditórias, ou melhor, binarismos fugazes. Como um idêntico processo reverbera paradoxalmente nas duas evidências etnográficas? $O$ fechamento relacional dos apartamentos também se sugere na abertura das praças da MOP? Marc Augé (1994) responderia tais questões partindo da oposição do lugar ao espaço, enquanto o primeiro é perpassado pela linguagem, pelas regras de convivência não formalizadas, pelos discursos que nele se pululam, o segundo remete às planícies não simbólicas; isto é, se o lugar é sentido e simbolizado, resvalando em seu bojo aspectos identitários, históricos e relacionais, então o espaço desponta enquanto figura antípoda, donde o social orgânico do primeiro desaparece para conferir a forma da tensão solitária, homóloga à narrativa de Lucie. Entretanto, o não lugar, o espaço não simbolizado de Augé não é a imagem negativa dum simples binarismo conceitual, na verdade, ele engendra complexidades palimpsésticas, quer dizer, o espaço nunca subsume totalmente o lugar e este, por sua vez, jamais ocupa a totalidade das superfícies daquele, tratam-se de inflexões oscilatórias, contrastes fugidios (AUGÉ, 1994).

Além disso, nos meandros deste movimento assimétrico da vaga apropriação do espaço para a efervescência do lugar, e vice-versa, não posso deixar de tecer "conexões parciais" (STRATHERN, 2014) com a etnologia indígena. Peço ao/a leitor/a que retorne algumas páginas e veja como a disposição dos apartamentos em relação à praça na MOP remete à aldeia bororo de Lévi-Strauss (1957), em que a distribuição das cabanas ao redor de um círculo tornava patente os gestos cotidianos e a vida coletiva bororo. Talvez não seja 
exagero estender os argumentos de Melatti (1974) sobre a forma circular dos casebres familiais kraô para os claustros das moradias. Aqui, como lá, o pátio central converte-se num âmbito de trocas, comensalidade e celebração.

$\mathrm{O}$ afastamento quase equipolente dos blocos em relação ao centro de convivência (MOP I) ou à praça (MOP II) alude também ao espaço habitado kayapó-xikrin (VIDAL, 1983), cujo anel circular entre as unidades residenciais tanto denota uma centralidade ontológica, visto como o centro do mundo social kayapó, quanto garante condições possíveis para a troca de insumos, preparação ritual e conversa sobre miudezas do cotidiano. Se por vezes, as quitinetes cerravam os entes num idêntico círculo, por outro, as margens do claustro entre os blocos conferiam a elas este caráter entreaberto. Assim, as praças se revertiam ora no ponto óptico equidistante da disciplina, ora no epicentro ontológico da vida de uns/as e outros/as. Tanto na praça, quanto nos apartamentos, o lugar habitado, amiúde, cedia temporalmente suas circunscrições ao espaço, afinal adentravam pelos portões e salas personagens até então desconhecidos aos/às residentes, visitantes inesperados/as, dentre outros/as.

De acordo com Casey (1996), uma das virtudes do lugar é sua habilidade de reunir e, para tanto, ele cria certos modos de contenção sobre o que é apresentado, o que permanece nas margens e se oculta, quais movimentos de sobreposição ou recuo. Assim, o lugar realiza uma configuração peculiar, dispondo móveis, ideias, pessoas dentro de determinados limites. Até mesmo quando demove os/as ocupantes para os liames de sua própria representação, o lugar consegue mantê-los/as manifestos/as no interior de suas fronteiras. De certa maneira, o lugar não o é, ele se consubstancia temporalmente nas experiências e nos corpos de seus/as ocupantes: "um determinado lugar assume as qualidades de seus ocupantes, refletindo essas qualidades em sua própria constituição e descrição e expressando-as na sua ocorrência como um evento: lugares não só são, eles acontecem” (CASEY, 1996, p. 27, tradução nossa).

Nesse sentido, o que tornava as salas dos apartamentos mais ou menos abertas para as pessoas dependia do evento e de certa dose de ocasionalidade. Por outras palavras, um aniversário fazia com que um/a dos/as intercambistas e moradores/as disponibilizassem uma lista de convidados/as na portaria, o que denota o caráter um tanto privativo do evento. Nem todos/as mopianos/as eram convidados/as a priori e os nomes dos/as externos/as previamente estavam contidos em uma listagem. Porém, isto era bastante contingencial, pois, às vezes, esses encontros se revertiam em grandes festas e até mesmo as postagens no Facebook denunciavam essa transição de status repentina. Nelas, os verbos estavam quase sempre flexionados no gerúndio: "está rolando uma festa no Limbo, venham!" ou "tá tendo festa aqui na quitinete dos boys intercambistas na II". Em outros momentos, os ritos impessoais predominavam.

Nas celebrações oficiais havia filas, lista de nomes, pagamentos, revistas feitas pelos/as próprios/as mopianos/as, tal como observei no decurso da festa junina. Nessas situações, quando a praça e o salão do centro de convivência recebiam muitos/as visitantes e as passagens para o estacionamento eram bloqueadas com cavaletes ou faixas listradas em amarelo, mesmo aí, podiam acontecer festas paralelas nos blocos que antecediam a 
comemoração oficial, funcionavam como "esquentas", conforme a gíria êmica, que às vezes, perduravam mais tempo que aquelas.

Vê-se então como espaço e lugar, individualidade solitária e construção de sentidos pela experiência se entrecruzam na MOP, retomando assim as considerações de Tuan (1983, p. 151): "o espaço transformar-se em lugar à medida que adquire definição e significado". Nas moradias, o simples ato de deixar as portas abertas recupera parte deste processo de transposição semântica do lugar:

Sabina: lá, já conhecemos nossos vizinhos, e eles, desde seu primeiro dia, foram muito, muito hospitaleiros, convidaram assim a jantar, a ter almoço, e desde esse dia como que temos uma relação muito boa, muito próxima [...] e bom desde esse dia, eles sempre convidam a jantar, a ter almoço, a fazer coisas juntos e como que sua porta sempre fica aberta e como que deixam que todo mundo entre e saia, entre e saia. Na verdade, eles ajudaram muito a que eso seja uma experiência assim muito bonita. [...] eles sabem que só as portas estão fechadas quando nós estamos peladas $o$ saímos de banhar. Tudo isso assim fechamos a porta, senão deixamos aberta.

Se partíssemos de uma interpretação cuja "a casa e a rua" aparecem como universos radicalmente invertidos um em relação ao outro, retratando espacialidades contrapostas, como propõe Roberto DaMatta (1997), o relato de Sabina apenas seguiria o curso teórico dos eventos, quer dizer, ao fechar as portas para se banhar ou trocar de roupa, ela e sua colega de quarto antepunham assim um recolhimento do privado face ao público, a casa cerra suas portas para rua, conforme as antelações teóricas de DaMatta (1997). Entretanto, tal escólio negligencia uma série de porosidades, zonas intersticiais entre um polo e outro em sua dupla acepção no tempo e no espaço (ARANTES, 1994), ou seja, as domesticidades sendo construídas através das práticas de comensalidade com os vizinhos, as maneiras como as relações se fazem e refazem ao longo dos meses, transpondo para o lugar, afetos, conflitos e o desenrolar das relações, e, inclusive, mesmo a porta fechada de Sabina, por vezes, pode deixar entrever "lances de intimidade" (ARANTES, 1994). Assim, as diferenças estruturantes do espaço social expressas no binômio "a casa e a rua" de DaMatta (1997) são reinterpretadas por Arantes (1994) de modo menos contundente e mais pautado em clivagens fluídas, negociações fragmentárias:

Ao tematizar as transposições e as densas liminaridades que formam os labirintos do centro de São Paulo, percorri algumas das fraturas físicas e simbólicas dessa paisagem. A fluidez do que observei levou-me a flexibilizar conceitos como território, fronteira, identidade, lugar e mesmo não-lugar. Ao explorar o modo como os conflitos se espacializam, deixo de privilegiar os traços distintivos dos espaços sociais, ou mesmo os 
contrastes semânticos que culturalmente os qualificam. (ARANTES, 1994, p. 201).

Arantes (1994) navega pelos territórios da Praça da Sé em São Paulo não como se estivessem equacionados numa lógica interna, mas, em troca, reconhece as múltiplas enunciações, as variadas experiências individuais de territorialidade que cingem qualquer possibilidade de um lugar convergente, elas, ao contrário, forjam marcos efêmeros, ambivalências fronteiriças. Logo, mais do que estarem previamente arquitetados, os lugares e espaços assumem formas passageiras, passíveis de acordos espúrios, transgressões e redes de ajuda mútua resultantes de moralidades urbanas díspares (ARANTES, 1994).

Um exemplo disso é ilustrado pela fala de Sabina, descrevendo como as relações de vizinhança produzem liminaridades por meio das quais os afetos se re-territorializam. Nas experiências diárias com seus vizinhos, eles sugeririam que ela se interessaria por um de seus amigos, residente na outra moradia, foi o que efetivamente aconteceu semanas depois em um desses jantares e cafés conjuntos:

Sabina: ao início eu não gostava dele, mas sim ele começou a falar a vir a procurar, como que minha porta sempre estava aberta [...] e de meus vizinhos sempre está aberta e ele sempre está lá. Como que a todo tempo estamos assim [...] querem beber um café, queremos a jogar.

No caso de Sabina, as relações com os vizinhos de apartamento lhe facultaram algumas trocas sociais rotineiras; aqui eles aparecem não só como pessoas de quem se depende para se transar uma noite, tal qual o caso de Marie-Claude, mas expressam as expectativas intersubjetivas em relação ao encontro afetivo de Sabina. Sem as tais relações de vizinhança, as portas abertas e as expectações socialmente produzidas é provável que ela não tivesse conhecido esse rapaz por intermédio dos vizinhos.

\section{De Buenos Aires a Pampulha: reciprocidade, táticas e percursos urbanos}

A centralidade das experiências na MOP se revela em vários excertos das entrevistas. $\mathrm{Na}$ medida em que nos distanciamos deste âmbito, muitas das ilações sobre as trajetórias afetivossexuais a partir da chegada em Belo Horizonte perdem o sentido. Isto, em parte, se deve à produção relacional e contextual dos encontros através da socialidade mopiana. A frase de Marie-Claude - "nunca saí da moradia" - aparece de modo análogo em outros relatos:

Tomas: siempre se trató de compartir cosas con otra gente, por ejemplo, salir a una fiesta, juntarse a comer, o también ir a ver concierto, recitales. Con las personas de la facultad no tengo tanta relación así como que con las personas na moradia. 
Franz: igual a maioria de mis cosas fuerón aquí en la moradia, muita fiesta en la moradia, muita vida na moradia. No sali muito a la ciudad eu fiquei nesse micromundo, assim, en la faculdade, ir aí como fala, Bar Cabral [...].

Pela descrição dos relatos de Tomas e Franz, a maioria de suas relações sociais dá-se no "micromundo" das moradias e nos eventos que ocorrem ali: festas, reuniões efêmeras, jantares, conversas nas praças. Nas poucas ocasiões que eles se deslocaram dali, parte dessa socialidade os acompanhava nas idas aos recitais, shows no Estádio Mineirão, nas andanças pela calçada do Cabral's Bar. Honza explica a escassa mobilidade dos/as residentes por Belo Horizonte pela noção de "preguiça", que é ratificada, de certa maneira, pela narrativa de Franz:

Honza: eu acho que a galera é muito preguiçosa, ficam na quitinete ou na praça, não querem sair muito, por exemplo, a ir no centro. A gente não vai muito no centro, não sai muito da moradia, né. Mas eu quando posso saio, vou pra igreja, vou pra Pampulha, vou pra centro.

Franz: dá preguiça también salir de noite. Como que aqui na moradia eu gusto muito de estar, como ficar acá. Eu priorizei muito en este intercâmbio las relaciones con a gente próxima así. Como que fue gusté, me ajudou a mi también a mudar como pessoa, como a faculdade não ocupou um lugar importante no intercâmbio y a ciudad tampoco, como que é a moradia a gente próxima. Eu estoy disfrutando muito da proximidade, eu fiz amigos muito próximos aqui y eso fue gracias que também fiquei muito en na moradia (grifos meus).

A frase de Franz, grifada, sintetiza a vivência de muitos/as intercambistas com os quais eu tive contato durante o trabalho de campo: nem a cidade e tampouco a vida acadêmica na UFMG ocupavam um lugar de relevo em suas experiências em Belo Horizonte. A existência social durante o intercâmbio era filtrada pelas lentes das moradias, pelas relações que ali se principiavam, para depois se deslocar a alguns módicos lugares da cidade. Não é à toa que Franz exclame "muita vida na moradia", pois um extenso lapso de tempo da sua vida no Brasil transcorreu entre os blocos e a praça da MOP.

O deslocamento dos/as intercambistas em Belo Horizonte, em geral, resumia-se em tomar o ônibus institucional da FUMP para comparecerem às aulas no Campus Pampulha da UFMG, e era geralmente nessas circunstâncias que eles/as se dirigiam, ao final da tarde, para o Cabral's Bar, uma vez que o estabelecimento se situa à frente da portaria da UFMG, na Avenida Antônio Carlos. Não era incomum também frequentarem o setor de serviços e os bares localizados nas saídas das duas moradias, na Avenida Fleming e, por vezes, fazerem 
caminhadas e exercícios físicos na orla da Lagoa da Pampulha, seguindo o fluxo da Fleming até o seu cruzamento com a Avenida Otacílio Negrão de Lima.

Por outras palavras, apenas a alguns metros da MOP II, através da Fleming, alcançavase o Complexo Arquitetônico da Pampulha, composto pela Lagoa, a Igreja de São Francisco de Assis, projetada por Oscar Niemeyer, o Museu de Arte da Pampulha, o Iate Tênis Clube e a Casa do Baile. Nas parcas vezes que os/as intercambistas ausentavam-se das MOP I e II, seus percursos urbanos tendiam a arranjar três tramas espaciais diversas, mas relativamente aproximadas entre si: o Campus Pampulha e os bares no seu entorno, a Avenida Fleming e as atrações na Lagoa, como se pode ver no mapa a seguir:

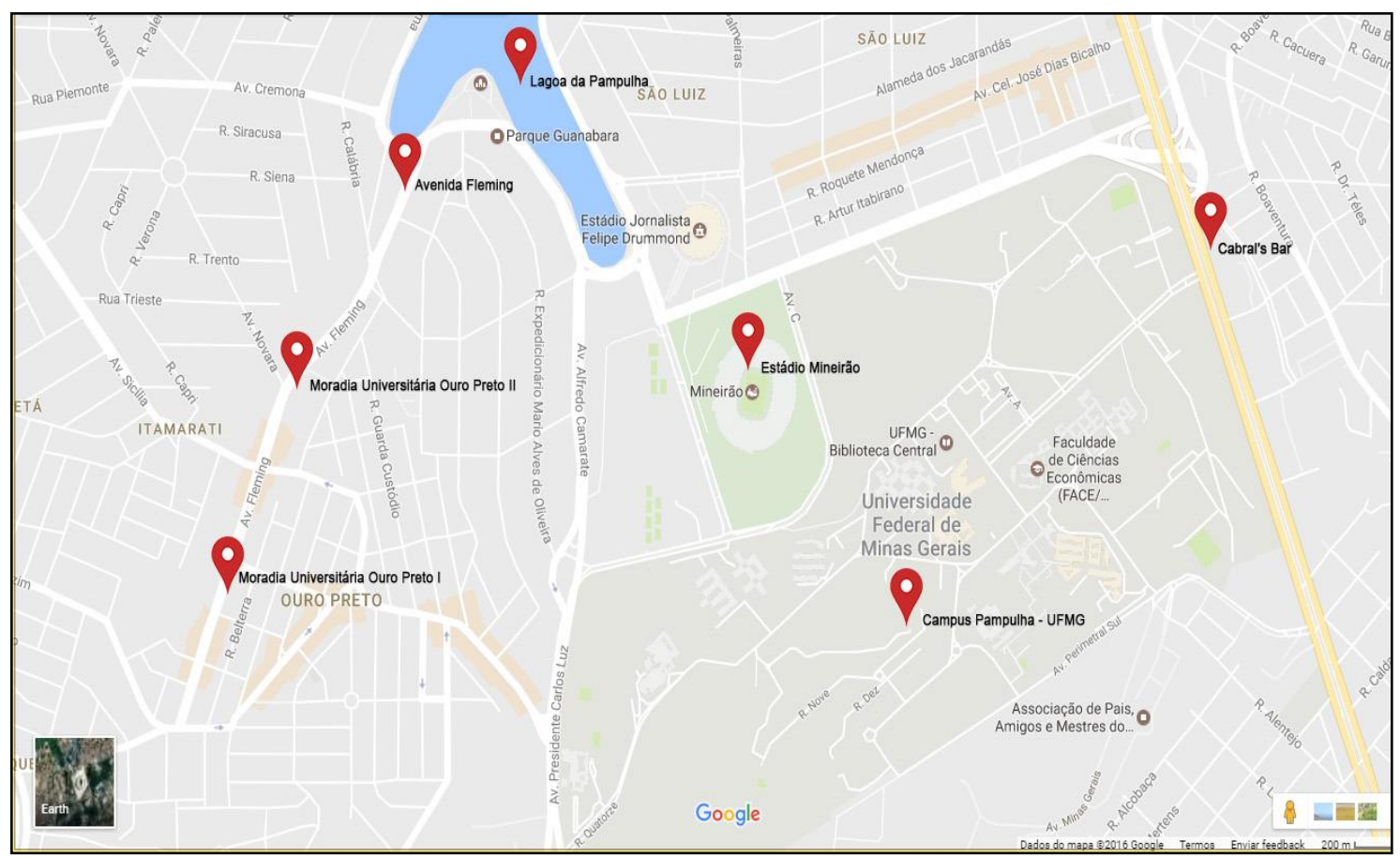

Figura 3. Mapa de deslocamentos dos/as intercambistas na região da Pampulha, Belo Horizonte/MG. Fonte: Google Maps, 2016.

A noção de "preguiça" explica em parte as junções destes trajetos individuais que podem ser lidos como pertencentes a um "circuito" para aplicar o conceito de Magnani (2002). Os fluxos desses/as estudantes relacionavam estabelecimentos que não conservavam entre si uma contiguidade espacial estrita, porquanto a comunicação possível entre os diversos ambientes fluía dentro dos predicados da socialidade mopiana. Os/As intercambistas quase sempre se deslocavam com seus/as conhecidos/as das moradias. Perspectivando por esse enlace, a noção de "preguiça" presente nas entrevistas de Franz e Honza guarda correspondência direta com as suas relações, que, em certo sentido, materializavam-se nesses mesmos deslocamentos: caso o grupo de amigos/as não fosse ao Cabral's Bar era bem pouco provável que o sujeito se locomovesse individualmente até lá. Além disso, havia outros fatores objetivos que incidiam na escassa mobilidade dos/as residentes, as bolsas de intercâmbio e a não disponibilidade de transportes públicos à noite: 
Franz: é muito caro viajar aqui, voltar sozinho também como estrangeiro é meio [...]. É el ônibus, es caro estar em el centro, porque uno tiene que gastar o dinheiro, también uno piensa depois voltar, às vezes eu tenho que voltar sozinho, como que não é muito legal de noite. Si dan cuenta que yo soy extranjero en centro não é legal, é peligroso.

Honza: eu não fui muitas vezes, eu acho que fui cinco vezes, muy pouco (para o centro), mas porque é muy caro o ônibus, pra mim é muito caro, né. Não quero gastar 7 e 40 reais só em ônibus, né [...] é muito, pra mim é muito, né. Então tem que ser uma coisa muito legal pra ir pra o centro, né, puntualmente.

Há poucas linhas de ônibus ligando o Bairro Ouro Preto ao centro de Belo Horizonte e, em geral, eles circulam até às duas da madrugada. Nesses testemunhos, a questão econômica dos deslocamentos pronuncia-se, todavia ela não se imbrica apenas ao valor das passagens ${ }^{6}$, mas também detém correlações com a condição financeira dos/as intercambistas. Aqueles/as que vêm pelo Programa Escala recebem uma bolsa semestral de, em média, R\$ 3.000,00 (três mil reais) para cobrir os gastos com alimentação, transporte, vestuário e materiais didáticos durante cinco meses.

Franz, por seu turno, remete à sensação de insegurança de trafegar sozinho pelo centro, julga ser "peligroso" para um estrangeiro voltar à noite, já que ele mesmo sofreu uma tentativa de assalto em uma dessas idas à região central de Belo Horizonte.

Sabina diz que prefere ir a festas e bares nas cercanias da Avenida Fleming, sumariando as questões anteriores por uma nova perspectiva, a distância até o centro: "o trajeto é muito longo para ir até lá”. Por exemplo, para ir até o Edifício Maletta, local amplamente frequentado pelos/as jovens universitários/as da UFMG, Sabina teria que tomar um ônibus na Fleming e só depois de quase uma hora e meia ela conseguiria alcançar a esquina da Avenida Augusto de Lima com a Rua da Bahia, donde se localiza o Maletta.

Ludvik, por sua vez, relata que encontra tudo que necessita na moradia: quando resolve jogar futebol, combina com os outros intercambistas e se direciona para a quadra na MOP I; caso queira dançar forró, frequenta as aulas de dança ${ }^{7}$ no centro de convivência; se tem fome, aguarda convites para jantar dos/as demais residentes. Por fim, ele justifica que, além da dificuldade para voltar de ônibus no período noturno, há a distância até o centro, arrematando as questões pelo seguinte prisma: "melhor ter festa aqui na própria casa".

Consoante a Gupta e Ferguson (2008), elucidar a transfiguração do espaço em lugar espaço significado - implica também reconhecer como as relações de poder se distribuem

\footnotetext{
${ }^{6} \mathrm{Na}$ época, os valores cobrados pelo transporte público em Belo Horizonte eram de R\$ 3,70 por trecho. Daí o cálculo de Honza, R\$ 7,40 para ir da moradia ao centro e fazer a viagem de retorno para o Bairro Ouro Preto.

${ }^{7}$ As moradias contam com projetos de convivência, desenvolvidos na forma de oficinas semanais. Até agosto de 2016, além das aulas de dança, havia os seguintes projetos: Condicionamento físico, Aulas de alemão, Yoga e Breakin'.
} 
espacialmente. Para os autores, a construção social do lugar não se dá ao acaso, como se estivesse suspensa num vácuo territorial, ao invés, tende a criar uma participação específica da localidade dentro de um sistema de espaços hierarquicamente organizados, ou seja, Gupta e Ferguson ao lado de Rodnan (2003) frisam que um lugar é quase sempre interseccionado por outros planos espaciais interdependentes a ele e ainda repercute as linhas de ação de certos marcadores sociais (gênero, raça, classe, dentre outros).

Em geral, a Pampulha é reconhecida por ser uma zona de residência de segmentos sociais mais abastados, sendo que o uso dos carros supre, amiúde, a parca oferta de linhas e horários de ônibus no Bairro Ouro Preto. No entanto, as políticas públicas em mobilidade urbana e as bolsas de intercâmbio respondem parcialmente ao mapa dos itinerários urbanos dos/as intercambistas, pois até aqui remetemos tão somente como as moradias foram imaginadas "dentro de determinaciones politico-económicas que tiene su propria lógica" (GUPTA; FERGUSON: 2008, p. 241). O acesso desses/as estudantes estrangeiros/as às diferentes regiões e bairros de Belo Horizonte perpassa ainda pelas relações de poder em que eles/as se encontram imbricados/as.

Michel de Certeau (1998) afirma que a cidade pensada pelos/as planejadores/as urbanos, arquitetos/as e pela administração pública é tomada por um simulacro teórico, como se crescesse sobre os cacos das práticas, isto é, ela só se avulta sob égide de sua lei anônima na medida em que faz desaparecer o entrelaçamento das práticas diárias. A cidade é tomada por um voyeurismo cego as suas próprias capilaridades, lá onde a geometria urbana perde suas amarras nos meandros da opaca mobilidade que se esbeira aqui e acolá. Mas mesmo ante as estratégias das construções visuais e panópticas, prevista pela malha e os contornos das ruas e esquinas, Certeau detecta a existência de práticas microbianas, táticas que se desenvolvem sob a tutela das redes de vigilância cujo intento é pugná-las. Ao fazer referência aos procedimentos avessos à cidade observadora, Certeau parece estar sinalizando exatamente para as práticas de resistência dos/as mopianos/as e as trocas de dádivas surgem enquanto pontos de condensação estáveis, criatividades sub-reptícias sem estarem completamente auguradas pelos dispositivos e discursos tanto dos/as funcionários/as da FUMP, bem como dos/as planejadores/as urbanos de Belo Horizonte (CERTEAU, 1998).

Destarte, o mapa de trajetos acima faz ser e aparecer o sistema de enunciação da capital mineira, mas também desloca e inventa outros costumes inauditos, por exemplo, assistir shows do lado de fora do Mineirão, se acotovelar em meio aos/as transeuntes no passeio em frente ao Cabral, encontrar com crushs discretamente nos bancos da Lagoa, mas talvez o ponto nevrálgico dos movimentos escorregadios ao panoptismo, se dê justamente no retorno para casa, quando eles/as devem ultrapassar o sistema de portarias das MOP para trocar afetos e estar com alguém. Se de um lado se insinua uma série de fragmentos dos enunciados urbanos revistos em segredo pelos/as intercambistas, por outro se averigua como as estratégias disciplinares de uma instituição transcendem suas jurisdições e influi nos trajetos citadinos de seus integrantes, se desdobrando assim tanto em sua conotação negativa, nos moldes da interdição à entrada de visitantes, quanto em seu esquema 
produtivo, quando seus membros se desengastam desta texturologia retrógada para buscar nichos afetivos em outros espaços (CERTEAU, 1998; FOUCAULT, 2010).

É aqui que me deparo com um vislumbre de Tuan (1983, p. 6): “[...] se pensamos o espaço como algo que permite movimento, então lugar é pausa; cada pausa no movimento torna possível que localização se transforme em lugar". Vejam que no meu desenho microbiano sobre as linhas de enunciação do Google Maps, os pontos vermelhos desempenham o sentido de uma pausa, um lugar habitado mesmo que transitoriamente pelos/as intercambistas. Ao mesmo tempo, estes vértices avermelhados se entremesclam num espaço maior de movimentos, de sintagmas e, porque não dizer, atravessados por zonas intersticiais, na esteira dos lampejos de Arantes (1994). Assim mesmo, não há nenhuma linha que liga um ponto ao outro e faço isso na espera que meus esmeros sutis deixem antever as suas propedêuticas, quer dizer, penso no conceito de multilocalidades de Rodnan (2003), nos diversos caminhos pelos quais as conexões entre lugares e vozes se interligam uns aos outros e resolvo não tracejar rotas para não dirimir a complexidade das relações de poder diferenciais entre os/as meus/as distintos/as interlocutores/as ao largo dos distintos lugares construídos e frequentados por elas e eles no decurso de suas trajetórias afetivas, seja em Belo Horizonte, seja na Argentina.

As socialidades que explicitam as vicissitudes nas trajetórias estão, portanto, um pouco além da Pampulha, se atam a experiências vividas em La Plata, Córdoba e Mendoza, por exemplo. Diferentes lugares se conjugam numa idêntica narrativa, ela mesma interseccionada por questões de classe, gênero, orientação sexual e etnia (VIDAL, 1983; FELD, 1996; BOURDIEU, 2002). Conforme as trajetórias se transmutam à medida que encarnam lugares (CASEY, 1996), elas põem em relação diferentes textos (CERTEAU, 1998), funcionam como palimpsestos que inscrevem e reescrevem expedientes tão dessemelhantes entre si: panoptismo, dádivas e sexualidades. Ademais, a própria região da Pampulha é ressignificada a partir do exterior (TILLEY, 1994) e sou propelido a conectar Gualeguaychú e Tucuman a Belo Horizonte, mormente, os fios relacionais que decolaram de Buenos Aires adquirem outros sentidos na Pampulha.

Ainda me recordo da minha última troca de palavras com Sabina. Em meio a reminiscências pessoais, Sabina surpreendeu-se com as amizades que fez no intercâmbio: como pessoas vindas de lugares distantes tornaram-se tão próximas de si? Quase a termo de nossa despedida, ela encontrou um desfecho para seus pensamentos num antigo adágio argentino e disse-me: "Dios los crea y el viento los amontona". Aqui e ali, a vida mopiana de Sabina sutilmente se imiscui à poética do ditado (BACHELARD, 1986). As memórias, mais uma vez, se impregnam dos sentidos do lugar.

\section{Referências Bibliográficas}

ARANTES, Antônio Augusto. A guerra dos lugares: sobre fronteiras simbólicas e liminaridades no espaço urbano. Revista do Patrimônio Histórico e Artístico Nacional, IPHAN, n. 23, pp. 191-203, 1994. 
AUGÉ, Marc. Não lugares: introdução a uma antropologia da supermodernidade. Campinas: Papirus, 1994.

BACHELARD, Gaston. La poética del espacio. México: Fondo de Cultura Económica, 1986. BENJAMIN, Walter. Flanêur. In: BENJAMIN, Walter. Obras escolhidas III: Charles Baudelaire, um lírico no auge do capitalismo. São Paulo: Ed. Brasiliense, 1994. pp. 185256.

BOURDIEU, Pierre. A casa ou o mundo ao contrário. In: CORREAA, Mariza (Org.). Ensaios sobre a África do Norte. Oeiras: Celta Editora, 2002. pp. 89-112.

CASEY, Edward S. How to get from space to place in a farily short stretch of time. In: FELD, Steven; BASSO, Keith (Org.). Senses of places. Santa Fé, Novo México: School of American Research Press, 1996. pp. 13-52.

CERTEAU, Michel de. Práticas de Espaço. In: CERTEAU, Michel de. A invenção do cotidiano, v. 1. 3 a ed. Petrópolis: Vozes, 1998. pp. 169-220.

DAMATTA, Roberto. A casa e a rua: espaço, cidadania, mulher e morte no Brasil. Rio de Janeiro: Rocco, 1997.

DIAS, M. A pesquisa tem "mironga": notas etnográficas sobre o fazer etnográfico. In: BONETTI, Aline; FLEISCHER, Soraya. Entre saias-justas e jogos de cintura: gênero e etnografia na antropologia brasileira recente. Porto Alegre: EDUNISC, 2006. pp. 54-68.

ELIAS, Norbert. A sociedade de corte: investigação sobre a sociologia da realeza e da aristocracia de corte. Rio de Janeiro: Jorge Zahar, 2001.

FELD, Steven. Waterfalls of song: na acoustemology of place resounding in Bosavi, Papua New Guinea. In: FELD, Steven; BASSO, Keith (Org.). Senses of places. Santa Fé, Novo México: School of American Research Press, 1996. pp. 91-135.

FELD, Steven; SILVA, Rita de Cácia Oeening da. Sons e sentidos: entrevista com Steven Feld. Revista de Antropologia, USP, v. 58, n. 1, pp. 439-468, 2015.

FOUCAULT, Michel. Vigiar e punir: história da violência nas prisões. 38. ed. Petrópolis: Vozes, 2010.

GASPAR-NETO, Verlan Valle. Na pegação: encontros homoeróticos masculinos em Juiz de Fora. Niterói: Editora UFF, 2014.

GUPTA, Akhil; FERGUSON, James. Más allá de la “cultura”: espacio, identidad y las políticas de la diferencia. Antípoda, n. 7, pp. 233-256, jul./dez. 2008.

HALL, Edward. A dimensão oculta. São Paulo: Martins Fontes, 2005.

LÉVI-STRAUSS, Claude. Bororo. In: LÉVI-STRAUSS, Claude. Tristes trópicos. São Paulo: Ed. Anhembi, 1957. pp. 208-258.

LÉVI-STRAUSS, Claude. As estruturas elementares do parentesco. Petropólis: Vozes; São Paulo: EDUSP, 1976.

MAGNANI, José Guilherme Cantor. De dentro e de perto: notas para uma etnografia urbana. Revista Brasileira de Ciências Sociais, São Paulo, v. 17, n. 49, pp. 11-29, jun. 2002.

MAUSS, Marcel. Ensaio sobre a dádiva: forma e razão da troca nas sociedades arcaicas. In: MAUSS, Marcel. Sociologia e Antropologia. São Paulo: Cosac Naify, 2003. pp. 184-314. 
MELATTI, Júlio Cezar. Por que a aldeia é redonda? Informativo FUNAI, ano III, n. 11/12, p. 34-41, 1974. Disponível em: < http://www.juliomelatti.pro.br/artigos/a-redonda.pdf>. Acesso em: 15 ago. 2017.

RODNAN, Margaret C. Empowering Place: multilocatity and multivocality. In: LOW,

Setha; LAWRENCE-ZÚNIGA, Denise. Locating Culture. The anthropology of space and a place. Blackwell Publishing, 2003. pp. 1-16.

RUBIN, Gayle. El tráfico de mujeres: notas sobre la "economía política" del sexo. Nueva Antropología, México, v. 8, n. 30, pp. 95-145, 1986.

STRATHERN, Marilyn. No limite de uma certa linguagem. Mana, v. 5, n. 2, pp. 157-175, 1999.

STRATHERN, Marilyn. Introdução. In: STRATHERN, M. O gênero da dádiva: problemas com as mulheres e problemas com a sociedade na Melanésia. Campinas: Editora da Unicamp, 2006. pp. 27-77.

STRATHERN, Marilyn. O efeito etnográfico e outros ensaios. São Paulo: Cosac Naify, 2014.

TILLEY, Christopher. A phenomenology of landscape: Places, Paths and Monuments. Oxford: Berg Publishers, 1994.

TUAN, Yi-Fu. Espaço e lugar. a perspectiva da experiência. Tradução de Lívia de Oliveira. São Paulo: Difel, 1983.

VIDAL, Lux. O espaço habitado entre os Kaiapo-xikrin (Jê) e os Parakanã (Tupi) do Médio Tocantins, Pará. In: NOVAES, S. C. (Orgs.) Habitações indígenas. São Paulo: Edusp, 1983. pp. 77-102.

\section{Antonio Augusto Oliveira Gonçalves}

É doutorando em Antropologia Social pela Universidade Federal de Goiás com mestrado em Sociologia pela Universidade Federal de Minas Gerais e graduação em Ciências Sociais pela Universidade Federal de Uberlândia.

Recebido em 12/02/2018

Aceito para publicação em 31/01/2019 